\title{
CORPOS NO COLÉGIO DE APLICAÇÃO DA UNIVERSIDADE FEDERAL DE
}

\section{SERGIPE}

\section{Anselmo Lima de Oliveira *}

Resumo: Este trabalho resulta de uma pesquisa desenvolvida com os objetivos de observar e analisar os discursos que ocorrem no Colégio de Aplicação da Universidade Federal de Sergipe, a partir da perspectiva de gênero e corpo. A pesquisa foi desenvolvida com docentes e discentes do ensino médio, por meio de uma abordagem qualitativa feita através de entrevistas. Utilizou-se para a análise de dados a análise de discurso na perspectiva pós-estruturalista (foucaultiana). Sugere-se que os discursos biológico, religioso, pedagógico, científico, moralista atravessam as falas dos participantes da pesquisa, produzindo representações sobre gênero, corpo e sexualidade, tanto submetendo quanto subvertendo a heteronormatividade presente no Colégio.

Palavras-chave: Educação. Corpo. Gênero. Discurso.

Introdução

Os corpos estão presentes no dia a dia escolar e são objetos de diversas problematizações. Dessa forma, "gestos, movimentos, sentidos são produzidos no espaço escolar e incorporados por meninos e meninas, tornam-se partes de seus corpos" (LOURO, 1997, p. 61). Essas características são suficientes para promover os mais diversos tipos de discriminações. Afinal, os olhares que se fixam nos corpos, localizando-os, distinguindo-os, enxergando-os, "podem vir a se constituir em marcas definidoras dos sujeitos" (LOURO, 2003, p. 1). Dessa forma, são atribuídos valores a essas marcas: menino/menina, heterossexual/homossexual, negro/branco etc.

O discurso biológico tradicional enxerga apenas o binômio macho/fêmea. Aquilo que escapa a tal construção científica é, portanto, lançado fora, pois "seu sexo biológico não coincide com seu desejo social de gênero" (LE BRETON, 2014, p. 21). A partir dessa perspectiva o corpo não aceito passa a fazer parte de uma fronteira cruel, habitada por chocarrices, vilipêndios, sendo extremamente desumanizado. Toda essa rejeição escolar e familiar tem produzido muito sofrimento e angústia nesses sujeitos, levando-os à ideia de abandono social.

$\mathrm{Na}$ atualidade, em meio a toda essa abertura tecnológica, é possível observar que as questões relacionadas ao corpo ainda são tabus no ambiente escolar. As escolas e os pais continuam resistentes à ideia de construir discussões mais amplas sobre esse tema. Isso sugere que tal relutância esteja associada ao fato da escola ter sido alicerçada em bases pedagógicas tradicionais. Como bem instrui

\footnotetext{
* Mestre em Educação pela Universidade Federal de Sergipe (UFS), Especialista em Gestão de Políticas Públicas pela UFS e Pesquisador do Grupo de Pesquisa: Educação, Formação, Processo de Trabalho e Relações de Gênero - CNPq.
} 
Freire (1996, p. 14), "o educador democrático não pode negar-se o dever de, na sua prática docente, reforçar a capacidade crítica do educando, sua curiosidade, sua insubmissão".

\section{Pressupostos teóricos}

A escola exerce, por séculos, funções de vigilância e punições, pois "[...] em qualquer sociedade, o corpo está preso no interior de poderes muito apertados, que lhe impõem limitações, proibições ou obrigações" (FOUCAULT, 2014, p. 134). Assim, o poder se toma do meu modus operandi, a verdade, onde, por meio da disciplina, exerce no sujeito suas funcionalidades.

Dias (2015), em Corpo, gênero e sexualidades: problematizando estereótipos, evidencia que docentes e discentes questionam processos normativos que visam a anulação de corpos, gerando, assim, conflitos entre a individualidade e o ideário social. Ainda, sugere que a escola necessita se reprogramar a partir da desconstrução de discursos tradicionais sobre corpos, enxergando-os nas suas formas multifacetadas. Então, a partir desse entendimento será possível compreender as diferenças. Para o autor, os debates sobre o tema corpo permanecem instáveis: ora avança em determinadas áreas do conhecimento, ora retroagem. Dias (2015) defende a não essencialidade do corpo, considerando-o mutável e fragmentado pelas experiências socioculturais. Para além, o autor reafirma a importância da centralidade dessa temática na educação: problematizando e desconstruindo estereótipos.

Para além, Le Breton (2014, p. 26) escreve que “[...] a reinvindicação gender queer liberta de toda e qualquer ancoragem biológica ou convenção social e inventa um indivíduo sem fronteiras de gênero [...]". Sugere-se, portanto, que os sujeitos não são obrigados a se fixar no binarismo menino/menina.

Para Butler (2000), o sexo é analisado como norma e prática regulatórias, evidenciada por meio do poder produtivo que demarca e diferencia os corpos. Isso sugere não haver diferença sexual na sua materialidade, mas assimetrias socioculturais construídas por meio de discursos heteronormativos. Dessa forma, infere-se que as normas regulatórias materializam os corpos com certa finalidade: dominação. Portanto, a norma não está determinada em si, mas a instabilidade dos corpos, o que conduz a visibilidade e, por conseguinte, estabilidade das normas.

Nas escolas - como em toda sociedade - ocorrem disputas pelo corpo. A partir desse instante se instala uma arena de poder, levando a heteronormatividade conduzir o corpo à indissociabilidade das normas regulatórias. Portanto, "forma-se então uma política das coerções que são um trabalho sobre o corpo [...]" (FOUCAULT, 2014, p. 135). Percebido socialmente, o corpo passa a ser concorrido e nele são inseridos os diversos padrões possíveis. Ao sofrer subversões, outras e novas normas são redefinidas, deslocadas e reinscritas no corpo, buscando, novamente, normatizá-lo. 
Os "viajantes pós-modernos" descritos por Louro (2004) se reportam aos sujeitos cambiantes, fragmentados e que não estão unificados às heteronormatividades. Para a autora, os sujeitos têm autonomia de habitar fronteiras e caminhar por diversos ambientes. Por desestabilizar as normativas sociais, esses sujeitos se tornam alvo das pedagogias tradicionais: sanções, exclusões e penas. Então, "ao instituir e demarcar o que é normal e aceito nesse espaço, a instituição escolar produz classificações e demarcações de anormalidades" (RIBEIRO, 2014, p. 124). Sugere-se com isso que os sujeitos desviantes - aqueles com comportamentos considerados disformes dos padrões estabelecidos - sofrem supressões e reprimendas sociais. Afinal, segundo Foucault (2014, p. 135), “[...] a disciplina fabrica assim corpos submissos e exercitados, corpos dóceis".

Na pesquisa Relações de gênero em livros didáticos de ciências: a produção de uma ciência masculina e heteronormativa, Cardoso (2014) traz uma discussão a respeito da produção da heteronormatividade nos livros didáticos de ciências. Segundo a autora, "nos livros didáticos analisados, tudo está bem dividido e delimitado: de um lado, machos, detentores da forma e fundamentais na corrida pela sobrevivência; do outro, fêmeas, mais frágeis, delicadas e a serviço da reprodução" (CARDODO, 2014, p. 4). Isso sugere que a escola promove papéis distintos para meninos e meninas. Ainda, que meninos, por serem "machos", dominam as meninas pelo fato de serem fêmeas.

Pensar corpo a partir da escola é compreendê-lo além de substratos biológicos, isento de questionamento e naturalmente dado. Como dito, o corpo é performático (Butler, 2000) e, por meio da linguagem, o "corpo parece como um meio passivo sobre o qual se inscrevem significados culturais" (BUTLER, 2003, p. 27).

Historicamente a escola foi construída a partir de discursos capazes de promover o certo, o errado, o exato, a norma. A certeza de que o corpo pode ser discutido, mas com inúmeras ressalvas. Salih (2012) descreve que "[...] recusar-se a dar repostas não constitui ignorância ou insensibilidade" (SALIH, 2012, p. 11). Sugere-se, aqui, que não precisamos ter a resposta certa para tudo, mas a capacidade de refletirmos sobre as diversas temáticas que circundam a escola.

\section{Metodologia}

O percurso metodológico desta pesquisa parte "do pressuposto de que teoria e método são indissociáveis e de que nossas opções metodológicas precisam fazer sentido dentro do referencial teórico no qual as inscrevemos" (MEYER, 2012, p. 48). Portanto, este estudo caminha diante de problematizações relacionadas ao corpo, a partir do ambiente escolar, especificamente no Colégio de Aplicação da Universidade Federal de Sergipe (CODAP/UFS).

Ao situar a metodologia da pesquisa como uma condição pedagógica, Paraíso (2012) compreende que, mesmo existindo métodos mais rígidos e/ou menos rígidos, a técnica sempre recai 
no "como fazer". Ainda que diversos métodos e técnicas estejam disponíveis, é fundamental traçar diálogos frequentes entre teoria e prática. Desse modo, a metodologia se torna pedagógica: busca-se o domínio das estruturas teóricas, observando as variações que ocorrem durante os processos. São essas (de)composições que permitem o ir e vir dos pesquisadores e pesquisadoras.

Sugere-se, então, que não se deve tomar o processo teórico-metodológico como algo rígido, indigerível e de difícil articulação. Ainda que seja necessário seguir o método - e este é fundamental é possível, também, improvisar, sem, com isso, causar distanciamentos da cientificidade, já que a

Metodologia é um termo tomado em nossas pesquisas de modo bem mais livre do que o sentido moderno atribuído ao termo método. Entendemos metodologia como um certo modo de perguntar, de interrogar, de formular questões e de construir problemas de pesquisa que é articulado a um conjunto de procedimentos de coleta de informações - que, em congruência com a própria teorização, preferimos chamar de produção de informação e de estratégias de descrição e análise [...]. (MEYER; PARAÍsO, 2012, p. 16).

Os métodos estão lá: são descritos e conceituados. As especificidades de cada pesquisa também estão presentes, uma vez que encontrar o ponto de convergência não é tarefa fácil. Alcançar as perguntas próximas, os questionamentos contíguos, observar o objeto de pesquisa a partir de várias perspectivas não gera conformidade, muito menos a certeza de que o caminho tomado foi suficiente. Compreende-se, portanto, que nesse percurso existem muitas bifurcações, e estas são necessárias para que os entendimentos sejam ampliados.

Ante o exposto, é razoável enfatizar que esta pesquisa se inscreve na área da ciência como uma pesquisa teórico-metodológica e, quanto à natureza, está evidenciado como um trabalho científico original, uma vez que a temática corpo foi problematizada pela primeira vez no CODAP/UFS. O percurso utilizado para alcançar os objetivos traz como forma de abordagem a pesquisa qualitativa. Afinal, "uma pesquisa é sempre, de alguma forma, um relato de longa viagem empreendida por um sujeito cujo olhar vasculha lugares muitas vezes já visitados" (DUARTE, 2002, p. 140). Sugere-se, dessa forma, que existem volatilidades significativas durante todo o percurso de uma pesquisa, tornando o caminho bastante sinuoso e suscetível às várias mudanças. Para tanto,

A vida de uma pesquisa é algo intrigante. Sujeita à sorte, ao tempo, aos lugares, à hora, ao perigo. $O$ improviso vem sempre turbilhoná-la. Pesquisar talvez seja mesmo ir por dentro da chuva, pelo meio de um oceano, sem guarda-chuva, sem barco. (OLIVEIRA, 2012, p. 279). 
Logo, é difícil encontrar trilhas seguras e quase sempre os improvisos estão à espreita. Então, pesquisar é um exercício arriscado, porém possibilita experimentar, acertar, errar. Durante essa estrada chamada pesquisa, viabiliza-se examinar sensações de temor, surpresas, dúvidas, mas também de alívio e liberdade. Por certo, "pesquisar é criar, e criar é problematizar" (CORAZZA, 2004, p. 27). Assim sendo, esse processo é contínuo, quase sempre desapegado à ideia de epílogo, mas se percebe inacabado e repleto de nuances.

Como dito, situada na abordagem qualitativa, esta pesquisa tem como perspectiva ouvir, tentar compreender, observar docentes e discentes do CODAP/UFS. Afinal, citando Golbenberg (1997), as pesquisadoras Silveira e Córdova (2009) descrevem que

A pesquisa qualitativa não se preocupa com representatividade numérica, mas, sim, com o aprofundamento da compreensão de um grupo social, de uma organização, etc. Os pesquisadores que adotam a abordagem qualitativa opõem-se ao pressuposto que defende um método único de pesquisa para todas as ciências, já que as ciências sociais têm sua especificidade, o que pressupõe uma metodologia própria. Assim, os pesquisadores qualitativos recusam o modelo positivista aplicado ao estudo da vida social, uma vez que o pesquisador não pode fazer julgamentos nem permitir que seus preconceitos e crenças contaminem a pesquisa. (GOLBENBERG, 1997, p. 34).

Diante disso, é imprescindível ressaltar que esta pesquisa está amparada na abordagem "pósestruturalista que se utiliza das concepções de poder e discurso de Foucault, bem como do pensamento que se centra nas questões da linguagem e da textualidade" (CARDOSO, 2012, p. 44). A partir desse viés, a pesquisadora Louro (2008) compreende que essas bases teóricas problematizam as dicotomias inerentes às produções científicas. Existem, desse modo, propostas de desconstrução das ideias de superioridade masculina sobre a feminina, vice-versa, visando a equacionar as relações entre ambos. Questiona-se, portanto, as representações da mulher dócil, frágil, delicada etc. em detrimento do homem forte, corajoso, sagaz etc. Nessa perspectiva, considera-se relevante destacar que a escola, amiúde, promove a reprodução desses comportamentos, distinguindo meninos de meninas, perpetuando, assim, as desigualdades entre os sujeitos sociais. Todavia, a escola também é lugar de desconstrução, uma vez que as reproduções sociais são questionadas a todo instante no ambiente escolar.

A partir do trabalho de campo realizado no CODAP/UFS, esta pesquisa está inserida na concepção de que é tarefa básica "explorar a dimensão política que caracteriza a construção de significados" (CARDOSO, 2012, p. 48). Também é considerável dizer que a opção metodológica desta pesquisa está, aqui, produzindo e criando outras/novas "realidades", pois, "é apenas uma forma, 
dentre muitas outras, de representar o observado" e está "permeada por um olhar interessado e carregado por concepções teóricas pré-estabelecidas" (CARDOSO, 2012, p. 48).

Assim, a pesquisa de campo realizada no CODAP/UFS evidenciou que "[...] o segredo está em descrever e problematizar 'enunciações', em mostrar os problemas de 'essências' mascaradas nos saberes [...]" (CARDOSO, 2012, p. 49). De forma despretensiosa ou não, alguns enunciados carregaram em si as marcas dos discursos construídos historicamente, que, por vezes, sinalizaram para as discriminações e preconceitos. Os sujeitos são capazes de criar e reinventar, ou seja, são construídos para produzir, "mas nesse processo de produção, há articulações com poderes, há estratégias e táticas que, ao serem acionadas na produção dos saberes, deixam no próprio discurso suas marcas" (CARDOSO, 2012, p. 49), demonstrando que todo saber também é político.

Ademais e objetivando subsidiar os debates inseridos nesta pesquisa, foram utilizados como aportes teóricos pós-estruturalistas: Foucault (1996, 2014, 2015a, 2015b), Louro (1997, 2000a, 2000b, 2001, 2003, 2004, 2010), Le Breton $(2007,2014)$, Butler $(2000,2003)$ e Paraíso $(2009,2012)$, além de outros.

O Projeto desta pesquisa foi encaminhado à Direção, vice Direção e Setor Técnico Pedagógico (SETEPE), cabendo a esses setores torná-lo disponível à comunidade. Entende-se que essa atitude foi relevante para que tanto a equipe pedagógica quanto a Direção tomassem conhecimento do tema. Desse modo, foram feitos os primeiros contatos com docentes e discentes, sendo, em seguida, entregue o Termo de Consentimento Livre e Esclarecido ${ }^{1}$ (TCLE) àqueles que participaram das entrevistas. Todas as condições descritas nesse documento foram informadas aos responsáveis dos participantes da pesquisa. Esta pesquisa foi submetida à Plataforma Brasil por meio do Comitê de Ética em Pesquisa da Universidade Federal de Sergipe (CEP/UFS), sendo em seguida aprovada.

Utilizou-se como técnicas de pesquisa a entrevista semiestruturada, a análise do PPP e do Regimento Interno do CODAP/UFS, demonstrando, assim, a relevância desses recursos. Essas técnicas por si só não podem explicar um fenômeno social, mas possibilitaram maior entendimento a respeito do contexto sociocultural estudado: como circulam os discursos que atravessam as falas de docentes e discentes, sobre as questões relacionadas ao tema corpo. Assim sendo, foram realizadas doze entrevistas semiestruturadas, sendo: sete docentes e cinco discentes.

As entrevistas foram realizadas em três ambientes: a sala de reunião da Direção, a sala do NEPEEB e a sala de reunião da área Ciências Humanas e suas Tecnologias. Esses locais foram escolhidos e acordados entre o entrevistador e entrevistados, visando a garantir privacidade e conforto. Todas as salas dispunham de ar-condicionado, boa iluminação, mesa e cadeiras. Mesmo primando por ambientes reservados, em determinados instantes as entrevistas foram interrompidas, pois algumas

\footnotetext{
${ }^{1}$ Este documento encontra-se no Apêndice A.
} 
pessoas acessavam as salas. Essas ocorrências geravam certo desvio de atenção, sem comprometer, com isso, o andamento das entrevistas.

As entrevistas ocorreram em dias distintos, sendo solicitado que os entrevistados ficassem livres para responder ou não as perguntas que seriam feitas. Em algumas entrevistas, a tensão inicial estava presente, mas, após alguns minutos, os entrevistados foram adquirindo confiança e liberdade, passando, assim, a explicitar informações importantes sobre o tema.

Todas as entrevistas foram gravadas e transcritas literalmente, objetivando garantir a compreensão do conteúdo. Após, utilizou-se como técnica de análise de dados, análise de discurso a partir da perspectiva foucaultiana. Dessa forma, foram utilizados fragmentos das falas de docentes e discentes, buscando, desse modo, produzir discussões a respeito das representações que estes possuíam a respeito da temática corpo.

\section{Análise de dados}

Ao fazer o questionamento: "mas, o que há, enfim, de tão perigoso no fato de as pessoas falarem e de seus discursos proliferarem indefinidamente? Onde, afinal, está o perigo?", Foucault $(1996$, p. 8) demonstra certa preocupação com os significantes inscritos nos diversos discursos. A partir dessa questão, o autor estabelece a hipótese de que nas sociedades existem controle, seleção, organização e redistribuição na produção do discurso e a consequência disso é a conspiração de poderes que se materializa na dominação.

Diante disso, busca analisar os enunciados proferidos tanto por docentes quanto por discentes do CODAP/UFS sobre as temáticas corpo. Diversos discursos encontrar-se-ão presentes nesses enunciados, ora perfilando convergências, ora se distanciando e produzindo suas "verdades". Antes, porém, é preciso destacar que as análises dos enunciados por vir são a "vontade de verdade" desta pesquisa.

Nessa perspectiva, buscou-se compreender melhor as relações entre gênero e corpo, descritas pelos entrevistados. Confrontando o discurso biológico, as enunciações sobre o tema demonstraram a possibilidade de um sujeito (des)construído, conforme a percepção de cada sujeito.

Eu concordo! É isso que eu tava falando no início. Eu acho que gênero, a gente parte da transformação do corpo e aí se você nasce homem e se considera homem, você é do gênero masculino. Mas se você passa a perceber que não é aquilo que você quer, não aceita aquilo que não é isso em você, que você nasceu só com o órgão, ali, errado. Aí você passa por uma transformação e aí é do gênero que você deseja, que você optou. Até porque o que a gente diz: a é homem ou mulher, o órgão que tá ali, o órgão reprodutor, o que tá reproduzindo. Se você tira aquilo ali, o que te define como homem e mulher? Sabe? Se você tira aquilo que, teoricamente, tá 
definindo o homem e a mulher, se você tira aquilo, se você muda aquilo, o que vai ser, agora, homem ou mulher tá na sua cabeça. A ideia de gênero vai tá na sua cabeça, não mais no seu órgão. $O$ corpo é um reflexo daquilo que você quer ser, certo? Sabe? Se você quer ser mulher, se você tem um corpo de mulher, você é mulher. Mas aí você tem um, um, você é homem, quer ser homem, tá, você é homem. Mas se você é mulher e quer ser homem, então um homem que quer ser uma mulher, então, quer fazer essa troca de sexo, essa troca de gênero, agora não vai ser mais o corpo da pessoa que vai definir isso, vai ser o que, realmente, quer ser. Ela vai passar por essa mudança pra se transformar naquilo que é o gênero que ela deseja ter. (Participante 11).

Contestando o discurso biológico que evidencia o corpo do sujeito como algo dado pela natureza e afirmando a ideia do gênero construído socialmente, enuncia-se:

Concordo! Concordo com isso! Até porque o gênero pode ser mudado também, e quem vai dizer qual o gênero da pessoa é ela, pelo que ela se considera e não pelo que as pessoas vão dizer o que ela é. Se ela nasceu como menino, ela vai ser menino, mas a pessoa pode mudar isso através do tempo, entendeu? A ciência já provou isso. (Participante 12).

Desse modo, demonstra-se, aqui, um poder-saber, em que o discurso é "[...] o poder do qual nos queremos apoderar" (FOUCAULT, 1996, p. 10). Para este participante, a ideia de que os sujeitos estão suscetíveis às mudanças ao longo da vida - ainda que nasçam com o "sexo" biológico masculino, podem, nesse ínterim, passar a se compreender mulher - traz implicações ao "se tratar de um poder que é exercido sobre os corpos dos sujeitos [...]" (LOURO, 1997, p. 41). Sugere-se, então, que pensar o corpo fora da esfera sociocultural é inconcebível, uma vez que o conjunto de enunciados que compõem o discurso biológico não se sustenta ao determinar o sujeito como "macho" ou "fêmea" a partir de uma fixação que produz distinção entre mulher e homem por meio dos órgãos sexuais. Afinal, essas diferenças biológicas são suficientes para promover as desigualdades sociais e, por conseguinte, atos e atitudes são postos dentro da naturalização, mascarando, assim, preconceitos e discriminações.

A pesquisa de Finco (2003) dá pistas a respeito dessas questões, apresentando a hipótese de que esses movimentos ocorrem e são ensinados a partir da educação infantil. Os marcadores sociais estão presentes desde a pré-escola e, dessa forma, meninas e meninos são ensinados a ocupar lugares distintos na escola, aprendem que determinadas brincadeiras são feitas para meninos, não para meninas e que certos brinquedos foram criados para meninas e não para meninos. Na escola, o corpo feminino não é construído da mesma forma que se constrói o masculino.

Outra questão que veio à tona nas entrevistas esteve relacionada aos livros didáticos utilizados no Colégio. Ou seja, buscou-se saber se o tema corpo é abordado nos livros didáticos do CODAP/UFS. Então, declarou-se que 
Fala! Eu até olhei no livro de Sociologia falando sobre... tanto sobre o gênero feminino, sobre violência, sobre as lutas do direito LGBT [Lésbicas, Gays, Bissexuais, Travestis, Transexuais e Transgêneros] e também a gente já apresentou trabalho sobre casamento homoafetivo, muita gente conversa sobre isso. É! Também teve um trabalho em Português, mas não foi em todas, não. Não foi em muitas. Algumas, só. (Participante 10).

Ainda que se tenha informado que o livro de Sociologia tratava sobre o tema, observou-se que não se tratava do livro didático utilizado no Colégio. Certo discente, por curiosidade, leu sobre o tema corpo em determinado livro e decidiu levar essa discussão para a sala de aula do CODAP/UFS. Evidencia-se, aqui, que alguns discentes buscam conhecer melhor a respeito do tema, relacionando as informações das mídias com o que é ensinado na escola. Desse modo, objetivando compreender se a temática corpo é discutida em outras disciplinas, informou-se que

Não! Eu acho que... a gente pode falar que é um assunto discutido, mas eu acho que não é um assunto discutido tanto como outras coisas são discutidas, sabe? Eu acho que é um assunto deixado meio de lado. Pode aparecer num livro, mas não é tão abordado, assim. Tem mais conversa entre aluno, assim, no cantinho da sala, tá, conversando, mas, de forma geral, não trata tanto assim, não. Tem muita gente que não concorda. Gera uma certa discussão. Não tem paciência pra entrar em discussão, porque sabe que não adianta falar nada, a pessoa vai tá te julgando, dizer que você tá errado. Aí você vai ter que dizer, né. (Participante 11).

O enunciado acima destaca que o tema corpo não é debatido de forma amplificada e que os discentes do Colégio buscam espaços reservados para falar sobre. Evidencia-se, ainda, que a temática gera discordâncias, impaciência e, por conseguinte, julgamentos. Sugere-se, portanto, que tais julgamentos estejam relacionados aos discursos religioso, moralista e biológico, todos alicerçados à ideia de "macho" e "fêmea". Ainda, evidencia-se a heterossexualidade como padrão social aceita. Entretanto, não se trata de compreender algo como certo ou errado, mas entender que na arena de debates é possível construir sujeitos capazes de respeitar as diferenças. Desse modo, a construção dos sujeitos faz relação tanto com concordância quanto com discordância, uma vez que os discursos que circulam nos debates são heterogêneos.

Buscou-se, em uma das entrevistas, saber se as temáticas gênero e corpo eram abordadas em sala de aula, se faziam parte da ementa e estavam presentes nos livros didáticos do Colégio. Assim, informou-se

Pronto. Em relação aos livros, normalmente, a gente não traz a parte de gênero. Livro? Não! Eu lembro, agora, que teve um concurso público pra Bahia, e tava me perguntando, pessoas que iriam fazer o concurso, se eu sabia qual era o livro que tinha pra poder trabalhar gênero em sala de aula 
com Ciências e Biologia. Não tem! A realidade é que nos livros didáticos que a gente utiliza, normalmente se fala sobre sexo biológico. Essa é a realidade. Quando o professor, e aí vai ser de cada um, quer trabalhar também a parte de orientação sexual, quer trabalhar a parte de gênero, aí seria por conta própria. No caso, é o que eu faço. Em relação a como eu trabalho, o que é que eu faço? Dependendo da turma, são assuntos que fazem parte do currículo para mim. Então, seria algo que vai ser visto, de qualquer maneira, durante aquele ano letivo. Exemplo: oitavo e primeiro ano, nesse momento. No caso de outras séries, se apresentar alguma discussão, alguma dúvida em torno desse assunto, mesmo que não seja o meu tema naquele momento, eu ainda abordo. Até pela necessidade em relação a diminuir preconceitos, diminuir a parte de discriminação, principalmente se tiver alguma pessoa identificada com o gênero diferente ou, então, que a gente colocar, entre essas, os colegas poderiam colocar como não sendo o normal. E essa é toda... o cuidado que eu tento fazer. Por que o que é normal? O que não é normal? Até porque isso não tem dentro da descrição como sendo normalidade, não. É só, apenas, uma característica de indivíduo. E, aí, eu trabalho nesse sentido. Por exemplo: esse ano, eu só tô com oitavo e sexto. No sexto ano, por enquanto, eu ainda não falei sobre isso. Em nenhum momento, eles tiveram algum questionamento, falando sobre, então, por enquanto, eu ainda não abordei essa parte de gênero no sexto ano. (Participante 4).

As enunciações acima trazem alguns pontos que podem ser classificados e problematizados: informa-se que os livros das disciplinas Ciências e Biologia não abordam a temática; os livros utilizados falam sobre o "sexo" biológico; quando há necessidade de trabalhar gênero ou orientação sexual, isso é feito por conta própria, ou seja, o docente é quem toma a decisão de discutir os temas em sala de aula; trabalhar gênero em sala de aula está diretamente relacionado ao tipo de turma; evidencia-se que o principal objetivo é minimizar os preconceitos e as discriminações. Sugere-se, aqui, que os preconceitos e discriminações estão presentes em sala de aula em virtude do discurso heteronormativo. Em outras palavras, as orientações sexuais consideradas distintas do padrão estabelecido são evidenciadas como marginais, anormais, ignoradas e perseguidas por práticas sociais fundamentadas nos discursos religioso, biológico e político.

Evidenciou-se, nas entrevistas, a importância de construir discussões sobre as temáticas corpo e gênero. Isso sugere a relevância dos temas, bem como necessidade de construir agendas capazes de estimular os debates.

$\mathrm{Na}$ escola, vejo falando pouco. Na escola, mesmo. Quem trazem esse assunto é os professores, mas dizer que a escola que traz, não. Mas os professores, o professor fala a opinião dele e ocorre um questionamento na sala de aula. (Participante 8).

Não tantos seminários assim na escola para trazer uma nova mentalidade para as pessoas. São os professores com suas opiniões, caráter, tentando formar as pessoas. Importante pra quem não sabe o que quer, ainda. Seria 
importante pra definir uma sexualidade. Quem já tem uma personalidade. É! Daquele aluno indeciso. Para as pessoas que já sabem, que já é formado, não é tão importante, assim. (Participante 9).

Os enunciados sugerem que o Colégio não proporciona discussões sistemáticas a respeito do tema corpo. Ainda, que a temática somente é abordada pelos docentes a partir dos questionamentos feitos pelos discentes, em sala de aula. Sugere-se também que o tema pode e deve ser debatido com discentes que possuem pouco ou nenhum conhecimento sobre o corpo. Tais evidências sugerem que a escola pode criar estratégias que envolvam a comunidade escolar, possibilitando discussões abertas e sistemáticas. Ainda, que o tema em tela diz respeito a todos que compõem o Colégio.

Observou-se que as discussões sobre corpo são bastante incipientes. Sugere-se, portanto, que isso ocorre devido às formas como a escola foi construída. Por anos a educação foi uma via de mão única, em que os discentes ouviam e aprendiam calados as ordens dos docentes.

Não fomos treinadas/os para conviver com a instabilidade, com as dúvidas ou com categorias cambiantes. Por isso é difícil lançar-se nessa perspectiva, subverter matrizes de pensamento, acolher a fluidez, numa arena que tradicionalmente tentou estabelecer verdades duráveis. (LOURO, 1997, p. 146).

A sociedade e a escola brasileiras foram alicerçadas sobre estruturas tradicionais bastante sólidas, quase intransponíveis. Dessa forma, o "rápido crepúsculo" descrito por Foucault (2015) permanece, ainda, erguido, porém ressignificado. Sugere-se, portanto, que os enunciados descritos nos discursos biológico, religioso, pedagógico, científico, moralista e político perpassam o tema corpo, construindo, assim, os mais variados tipos de sujeitos sociais.

\section{Considerações finais}

Nada pronto, nada definido. Tudo sempre em construção. Tudo ainda por se dizer... Nascendo... Brotando... Sublimando... O que seria de nós sem a expectativa da continuação? (Nilson Furtado).

Foram tantas questões discutidas, tantas problematizações que, a partir delas, esse aprendiz apresenta, aqui, alguns pontos a serem considerados e refletidos, pois servirão de lugar de partida para possíveis mudanças e anseios das vozes que gritam neste texto. Não intento arrolar esses pontos apenas como um resumo dos assuntos mais destacados desta investigação. Pretendo, também, explicitar meu posicionamento ante ao que foi presenciado, vivido, observado e descrito na pesquisa de campo. 
Observou-se que o discurso biológico - presente em diversos enunciados - está bem enraizado no currículo escolar do CODAP/UFS. Ainda, que algumas falas estão baseadas no senso comum e tendem a naturalizar diversas situações relacionadas ao tema. Isso preocupa, porque as discriminações e preconceitos podem ser tomados como algo natural, normal, abandonando, por certo, o senso crítico descrito no PPP do Colégio.

Ainda que os participantes da pesquisa expressem a necessidade de debates sobre o tema, observou-se que o Colégio não está devidamente estruturado pedagogicamente para promover essas discussões, pois o conhecimento sobre o tema limita-se ao senso comum. Desse modo, é imprescindível que o Colégio produza e estabeleça políticas pedagógicas integradas à temática, capazes de mover o conhecimento a respeito das questões apontadas por docentes e discentes.

Retomando a hipótese desta pesquisa, confirmo que, apesar do Colégio ter como finalidade "servir de campo de observação, pesquisa, experimentação, demonstração, desenvolvimento e aplicação de métodos e técnicas de ensino, de acordo com o Decreto-Lei 269/67" (CODAP/UFS, 2008, p. 2), o tema corpo não é problematizado de forma amplificada nessa instituição. Ainda, observou-se que esporádicos debates sobre o tema ocorrem a partir das necessidades individuais e autônomas dos docentes, bem como pela "vontade de saber" dos discentes.

\title{
BODIES IN THE APPLICATION COLLEGE OF THE FEDERAL UNIVERSITY OF SERGIPE
}

\begin{abstract}
This work results from a research carried out with the objective to observe and analyze the speeches that occur in the application School of the Federal University of Sergipe, based on the perspective of gender and body. This is a qualitative research and it was developed with teachers and high school students through interviews. Discourse analysis was used in the post-structuralism perspective (by Foucault). It is suggested that the biological, religious, educational, scientific and moralistic discourses cross the statements of the participants, producing representations of gender and body, both submitting and subverting the heteronormativity present in the School.
\end{abstract}

Keywords: Education. Body. Gender. Speech.

Referências

BAKHTIN, M. Estética da Criação Verbal. São Paulo: Martins Fontes, 1992.

DIONÍSIO, A. P. Gêneros textuais e multimodalidade. In: KARWOSKI, A. M.; GAYDECZKA, B.; BRITO, K. S. (Org.). Gêneros textuais: reflexões e ensino. São Paulo: Parábola Editorial, 2005.

BUTLER, J. Corpos que Pesam: sobre os limites discursos do sexo. In: LOURO, Guacira Lopes (org.). 0 Corpo Educado: pedagogias da sexualidade. 3a ed. Belo Horizonte: Autêntica, 2000.

BUTLER, J. Problemas de gênero: feminismo e subversão da identidade. Rio de Janeiro: Civilização Brasileira, 2003. 
CARDOSO, L. R. Homo Experimentalis [manuscrito]: dispositivo da experimentação e tecnologias de subjetivação no currículo de aulas experimentais de ciências. Tese (Doutorado em Educação) Universidade Federal de Minas Gerais, 2012.

CARDOSO, L. R. Relações de gênero em livros didáticos de ciências: a produção de uma ciência masculina e heteronormativa Disponível em: https://www.enalic2014.com.br/anais/anexos/3253.pdf>. Acesso em: 28 jan. 2016.

CORAZZA, S. Pesquisar o acontecimento: estudo em XII exemplos. In: TADEU, Tomaz; CORAZZA, Sandra; ZORDAN, Paola (Org.). Linhas de escrita. Belo Horizonte: Autêntica, 2004, p. 7-78.

DIAS, A. F. Corpo, gênero e sexualidades. Problematizando estereótipos. Revista Retratos da Escola, Brasília, v. 9, n 16, jan/jun 2015, p. 73-90.

DUARTE, R. Pesquisa Qualitativa: reflexões sobre o trabalho de campo. Cadernos de Pesquisa, n. 115, p. 139-154, março/2002.

FINCO, D. Relações de gênero nas brincadeiras de meninos e meninas na educação infantil. Revista Pro-Posições, v. 14, n. 3 (42) - set./dez. 2003.

FOUCAULT, M. A Ordem do Discurso: aula inaugural no Collège de France, em 1970. São Paulo, Edições Loyola, 1996.

FOUCAULT, M. Vigiar e Punir: nascimento da prisão. Petrópolis, RJ: Vozes, 2014.

FOUCAULT, M. História da sexualidade 1: A vontade de saber. 2a ed. - São Paulo, Paz e Terra, 2015.

FREIRE, P. Pedagogia da Autonomia: saberes necessários à prática educativa. São Paulo: Paz e Terra, 1996.

GOLBENBERG, M. A arte de pesquisa. Rio de Janeiro: Record, 1997.

LE BRETON, D. Corpo, Gênero, Identidade. In: FERRARI, Anderson. et al. Corpo, Gênero e Sexualidade. Lavras: UFLA, 2014.

LOURO, G. L. Gênero, Sexualidade e Educação. Uma perspectiva Pós-Estruturalista. Petrópolis, RJ: Vozes, 1997.

LOURO, Guacira Lopes. Corpos que escapam. Revista Estudos Feministas, n. 4, ago/dez, 2003.

LOURO, G. L. Um Corpo Estranho: Ensaios sobre sexualidade e teoria queer. Belo Horizonte: Autêntica Editora, 2004.

MEYER, D. E. Metodologias de Pesquisas Pós-Críticas em Educação. Belo Horizonte, Mazza Edições, 2012.

OLIVEIRA. T. R. M. Mapas, dança, desenhos: a cartografia como método de pesquisa em educação.. In: MEYER, Dagmar Estermann: PARAÍSO, Marlucy Alves (Org.). Metodologias de Pesquisas Pós-Críticas em Educação. Belo Horizonte: Mazza Edições, 2012, p. 279-303. 
PARAíSO, M. A. (Org.). Metodologias de Pesquisas Pós-Críticas em Educação. Belo Horizonte: Mazza Edições, 2012, p. 279-303.

RIBEIRO, P. R. C. Os corpos no espaço escolar: (re)configurações dos/as alunos/as anormais em tempos pós-modernos. In: FERRARI, Anderson. et al. Corpo, Gênero e Sexualidade. Lavras: UFLA, 2014.

SALIH, S. Judith Butler e a Teoria Queer. Belo Horizonte: Autêntica Editora, 2012. 